Nachholfaktor

\section{Irrungen und Verwirrungen}

In seinem Kommentar „Nachholfaktor ist zurück - gut so?“ befürwortet Martin Werding (2022) die Wiedereinsetzung des Nachholfaktors - eigentlich Ausgleichsfaktor. Ohne diesen, so seine Begründung, würden die Renten schneller steigen als die Löhne. Mit der Losung, „die Rente folgt den Löhnen“, wird die Reaktivierung des Ausgleichsfaktors gefordert. Diese Argumentation tragen einige Ökonomen seit rund anderthalb Jahren wiederholt vor, ohne dass diese richtiger wird. Viel mehr führt sie - bewusst oder nicht - in die Irre. Letztlich sollen die Rentenerhöhungen wieder dem Beitragssatzdogma untergeordnet werden. Reaktiviert würde in Wahrheit also die Politik des sinkenden Rentenniveaus.

Die Materie ist komplex und begünstigt die Irrungen und Verwirrungen. Die Fakten sprechen jedenfalls eine klare Sprache: von 2018 bis 2025 steigen die Renten um 19,3\% und die Löhne um 19,6\% laut Rentenversicherungsbericht 2021. Wird beachtet, dass die Renten mit zwei Jahren Verzögerung der Lohnentwicklung folgen, dann steigen die Löhne von 2018 bis 2023 um 12,8\%, die Renten von 2020 bis 2025 aber nur um 11,8\%. Denn bis 2035 steigen die Löhne um rund $60,8 \%$, die Renten aber nur um 46,7\%. Die Renten steigen also schon im geltenden Recht langsamer als die Löhne. Den Ausgleichsfaktor zu reaktivieren vergrößert diese Lücke.

Werding behauptet, dass aufgrund des Rückgangs der maßgeblichen Versichertenlöhne 2020 und der Wirkung der Schutzklausel ohne Ausgleichsfaktor das Rentenniveau dauerhaft deutlich höher liegen würde. Hier lässt er wesentliche Fakten unerwähnt: Erstens: Die für die Rentenanpassung letztlich maßgeblichen Versichertenlöhne - die beitragspflichtigen Entgelte - sind 2020 um rund 1,7\% gestiegen. Gesunken sind 2020 die Entgelte nach VGR-Statistik und auch diese nur um 0,28 \% - im Wesentlichen durch die Kurzarbeit. Zweitens: In der Anpassungsformel wies der Lohnfaktor ein Minus von 2,34 \% auf. Dies besteht aber zu rund 2,1 Prozentpunkten aus einem statistischen Sondereffekt, da ab 2019 in die Berechnung des Lohns rund 900.000 Minijobber zusätzlich einbezogen würden - ohne diesen verzerrenden Effekt würde der Lohnfaktor ein Minus von 0,26\% ausweisen. Die Schutzklausel hat verhindert, dass die Renten um diesen Statistikeffekt gekürzt würden - ihn nun nachzuholen würde die Renten dauerhaft um über $2 \%$ unter die Lohnentwicklung drücken. Drittens: Der statistische Sondereffekt geht auch

(C) Der/die Autor:in 2022. Open Access: Dieser Artikel wird unter der Creative Commons Namensnennung 4.0 International Lizenz veröffentlicht (creativecommons.org/licenses/by/4.0/deed.de).

Open Access wird durch die ZBW - Leibniz-Informationszentrum Wirtschaft gefördert. in das Rentenniveau ein. Dieses fällt allein dadurch rechnerisch rund einen Prozentpunkt höher aus, ohne dass sich die Löhne oder Renten verändert hätten - weder absolut noch relativ zueinander. Viertens: Bei der Rentenanpassung 2021 ergab der Nachhaltigkeitsfaktor eine weitere Minderung von 0,9\%. Ohne Schutzklausel wären die Renten um diese 0,9\% zusätzlich gekürzt worden. Genau diese Rentenkürzung soll nach Werding auch nachgeholt werden, wenn er ausführt, dass mit dem Ausgleichsfaktor wieder der in den „einschlägigen Standardregeln verankerte Status quo wiederhergestellt" würde.

Vordergründig argumentiert Werding mit der Lohnentwicklung. Der Vorschlag zielt aber darauf, die Niveausicherungsklausel von $48 \%$ (Haltelinie) zu unterlaufen, in dem die „eigentlich“ erwünschten Rentenkürzungen spätestens nach 2025 nachgeholt werden. Aber auch, da er sich auf das durch den Sondereffekt überhöhte Niveau bezieht und die Haltelinie damit faktisch auf $46,9 \%$ absenkt.

Die Debatte um den Ausgleichsfaktor entbehrt aber nicht einem Kern an Wahrheit, über den zu streiten sich lohnen dürfte: Aus technischen Gründen der Datenverfügbarkeit wird bei der Rentenanpassung sowohl auf die Entwicklung der Löhne nach VGR im Vorjahr (t-1) als auch für das vorvergangene Jahr (t-2) auf die Differenz der Löhne nach VGR zu den beitragspflichtigen Löhnen rekurriert. Die Löhne nach VGR sanken 2020 um 0,28\%. Daher betrug der Lohnfaktor bei der Rentenanpassung 2021 ohne Sondereffekt minus $0,26 \%$. Dies kürzte die Renten wegen der Schutzklausel nicht. 2022 wird das Minus der VGR-Löhne über die Differenzbildung die Renten stärker erhöhen als die Löhne stiegen. Diese 0,26\% nachzuholen wäre somit tatsächlich begründbar. Angesichts unzureichender Renten und hoher Inflation könnte man es aber auch sein lassen.

In jedem Fall sollte die Debatte zum Anlass genommen werden, endlich die bestehenden Anpassungsmechanismen von Grund auf neu festzulegen. Als wenig zielführend haben sich Konzepte eines quasi überhistorischen, kybernetischen Anpassungsmechanismus bewiesen. Politische Wertvorstellungen in komplexe mathematische Formeln und Regeln zu gießen, löst die Verteilungskonflikte nicht. Im Speziellen aber müssen der Lohn- und Nachhaltigkeitsfaktor auf den Prüfstand. Sie tragen ganz wesentlich zu den inkohärenten Schwankungen bei der Rentenanpassung bei.

Ingo Schäfer

Deutscher Gewerkschaftsbund (DGB)

\section{Literatur}

Werding, M. (2022), Rente: Nachholfaktor ist zurück - gut so?, Wirtschaftsdienst, 102(1), 5. 